\title{
ABSTRACTS FOR POSTER PRESENTATION
}

\author{
Early Pregnancy/Pregnancy Recognition
}

\section{HIGH PROTEIN DIET INHIBITS INNER CELL MASS FORMATION AND INCREASES APOPTOSIS IN MOUSE BLASTOCYSTS DEVELOPED IN VIVO BY INCREASING THE LEVELS OF AMMONIUM IN THE REPRODUCTIVE TRACT}

\author{
D.K. Gardner, K.S. Stilley, and M. Lane \\ Colorado Center for Reproductive Medicine, Englewood, CA, USA. email: dgardner@colocrm.com
}

\begin{abstract}
Ammonium is known to adversely affect the development of mouse embryos in culture. Specifically, ammonium has been found to impair inner cell (ICM) mass formation, increase apoptosis, retard fetal development following embryo transfer and induce exencephaly. Significantly, high protein diets in cattle lead to reduced fecundity. This has been linked to elevated urea levels within fluid of the female tract. In this study we have determined the effects of a high protein diet for mice on the levels of ammonium within the female tract and the effects of such a diet on the development and viability of blastocysts developed in vivo. Outbred mice (CF1) were fed a diet of either $25 \%$ (high protein) or $14 \%$ (control) protein for 4 weeks. Females were superovulated and mated to males of the same strain. In 24 mice, oviduct fluid was collected at $22 \mathrm{~h}$ post hCG. Ammonium in the oviduct fluid was then quantitated fluorometrically. From other animals, blastocysts were flushed $92 \mathrm{~h}$ post hCG and analyzed. Blastocyst differentiation and apoptotic indices were determined. Values are mean \pm SEM. Data were analysed using Student's $t$-test. The levels of ammonium in the oviduct were significantly higher $(P<0.01)$ in females fed the high protein $\operatorname{diet}(356 \pm 43 \mu \mathrm{M})$ compared to the control $(68 \pm 13 \mu \mathrm{M})(n=12$ in each group). Blastocysts $(n=139)$ from females fed the high protein diet had significantly lower total $(43.4 \pm 1.1 ; P<0.05)$ and ICM cell numbers $(12.7 \pm 0.4 ; P<0.01)$, compared to the control group ( $46.8 \pm 0.9$ and $15.4 \pm 0.4$ respectively; $n=124)$. Furthermore, blastocysts from animals fed a high protein diet had a significantly higher apoptotic index $(8.7 \pm 1.4 ; P<0.01)$ compared to the control group $(2.0 \pm 0.5)$. These data show that consumption of a high protein diet results in the excess accumulation of ammonium in the fluid of the female reproductive tract of mice. These high levels of ammonium subsequently impair the formation of the fetal progenitor cells and increase cell death at the blastocyst stage. These data from in vivo-developed mouse blastocysts are similar to those for blastocysts developed in culture in the presence of $300 \mu \mathrm{M}$ ammonium. Therefore, it is not advisable to maintain mice on a high protein diet. These data have significant implications for animal breeding, and for patients attempting IVF treatment.
\end{abstract}

\section{THE EFFECT OF ANTI-CD44 ON EMBRYO IMPLANTATION IN RABBITS}

M.J. Illera, P. Bermejo, J. Hernandez, A. Gonzalez, and J.C. Illera

Universidad Complutense de Madrid. Facultad de Veterinaria, Madrid, Spain. email: mjillera@vet.ucm.es

Cellular adhesion molecules are thought to be responsible in embryo attachment in human and animals. Blastocyst attachment to the lining of the mammalian uterus during early implantation involves the initial apposition of the trophoblast to the uterine epithelial surface. A number of cell 
surface molecules have been implicated in the initial attachment reaction between trophectoderm and maternal surface epithelium, these include heparin-binding epidermal growth factor (HB-EGF), trophinin, CD44, integrins and extra cellular matrix molecules such as osteopontin (OPN) each of which exhibit elevated levels of expression at the time of implantation. CD44 is a membrane glycoprotein that is present in a variety of isoforms and is considered to be the major cell surface receptor for hyaluronan. The aim of these work was to study the effect of CD44 on embryo implantation. The rabbit is potentially an excellent model for study of implantation because it is an obligate ovulator, and therefore pregnancy can be precisely timed. Adult New Zealand rabbit females $(n=12)$ were naturally inseminated with a buck of proven fertility. The day of coitus was counted as 'Day 0' of pregnancy. To determine the effect of CD44 at the time of implantation, the animals were divided in three groups: group A (four animals): received $100 \mu \mathrm{g}$ of anti-CD44/mL in an intraperitoneal injection on day 4.5 of pregnancy; group B (four animals), via mid-ventral laparotomies on day $6.5 \mathrm{p} . \mathrm{c}$ animals received an injection of $20 \mu \mathrm{g}$ of anti-CD44 on the right horn $(0.5 \mathrm{~mL}$ each, from the ovarian end to the cervix). All these treatments were performed in the right horn. Each animal served as her own control with the left uterine horn receiving $0.5 \mathrm{~mL}$ of saline Group C (four animals): This was the control group; two animals received an injection of $2 \mathrm{~mL}$ of saline and the other two received $0.5 \mathrm{~mL}$ of saline in each uterine horn. Finally, each animal was sacrificed on Day 10 of the pregnancy, the uterus was removed, and the number of implants were counted in each uterine horn. In the group A: a mean of $4.5 \pm 0.47$ s.e.m implants were found in the right and on the left side. In group B, a profound reduction in implantation sites was found with the anti-CD44 injected into the uterine horn, a mean of 0 implants in the right uterine horn compared with 3.5 implants on the left side $P<0.0001$. Group C showed 4.25 implants on the right horn and 5.5 on the left horn; no statistical differences were found. Conclusion: the intraperitoneal injection of the anti-CD44 slightly reduced the number of embryos implanted but this reduction was not statistically significant. Anti-CD44 injected intrauterine affected seriously the embryo survival at the time of implantation.

\title{
138 EARLY EMBRYO MORTALITY IN BUFFALO (BUBALUS BUBALIS) DURING THE SPRING PERIOD
}

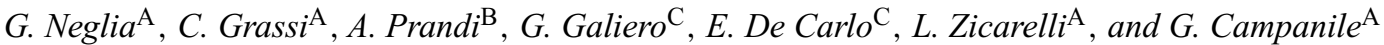

A DISCIZIA, Federico II University, Naples, Italy; ${ }^{\mathrm{B} D S A}$, Udine University, Italy; ${ }^{\mathrm{C}}$ IZSM, Salerno section, Italy. email: neglia@unina.it

Embryo development is linked to several factors, such as intrinsic defects within the embryo, an inadequate maternal environment or failure of maternal response to embryonic signals. Reproductive seasonality in buffalo species (Bubalus bubalis) is responsible for the lower reliability of the pregnancy diagnosis by progesterone assay in spring, probably due to the high incidence of early embryo mortality (EEM) for hormonal reasons (Campanile et al., 1989; Proc. 2th National Meeting 'Studio dell'efficienza riproduttiva degli animali di interesse zootecnico': 51-57). The aim of the study was to identify the causes of EEM in buffaloes inseminated during the spring period. Italian Mediterranean Buffalo cows $(n=209)$ in a good state of health were synchronized using the Ovsynch-TAI Program (Pursley et al., 1995 Theriogenology 44, 915-923) and inseminated 16 and 40 hours after the second administration of GnRH. Artificial inseminations were performed by the same technician. Ten to 20 days after the first insemination two blood samples were collected from each animal for assessing P4 levels by RIA. Days 24 and 40 after the first insemination, pregnancy diagnosis was assessed by rectal ultrasonography (Aloka SSD-500) with a $5 \mathrm{MHz}$ sector scanner. In animals with EEM a uterine flushing was carried out and recovered fluid was analyzed for the principal infectious agents. Microbiological analyses were carried out according to Quinn et al. (1994 Clinical Veterinary Microbiology, Wolfe Publishing, Mosby, Europe) and a PCR analysis was performed only for Bubaline Herpes Virus (BuHV1), Toxoplasma and Neospora. Statistical analysis was assessed by Student's $t$-test. The incidence of cyclic buffaloes after synchronization treatment (94\%) and pregnancy rate at 40 days (34.4\%) were similar to those reported in a previous study (Neglia et al., 2003 Theriogenology 60, 125-133). EEM between 24 and 40 days was $45 \%$ and only in 9 buffaloes (15.3\%), these results correlated with the presence of infectious agents (Streptococcus spp. group B and G, Bacillus licheniformis, Proteus mirabilis, Staphylococcus spp.). P4 levels on Day 10 were higher $(P<0.05)$ in pregnant (P) buffaloes than in those with EEM. On Day 20, P4 levels were higher $(P<0.01)$ in $\mathrm{P}$ buffaloes than in those with EEM and those not pregnant. It is hypothesized that the reduced activity of hypophysis, correlated with an increase in hours of light, may be responsible for decreased P4 concentrations and EEM in buffalo.

Table 1. P4 blood levels in pregnant (P) and non pregnant (NP) buffaloes and in buffaloes with EEM 10 and 20 days after insemination

\begin{tabular}{lccc}
\hline Group & $n$ & P4 at 10 days $\left(\mathrm{ng} \mathrm{mL}^{-1}\right)$ & P4 at 20 days $\left(\mathrm{ng} \mathrm{mL}^{-1}\right)$ \\
\hline P & 72 & $3.9 \pm 2.3^{\mathrm{a}}$ & $3.8 \pm 1.8^{\mathrm{A}}$ \\
NP & 78 & $3.5 \pm 2.3^{\mathrm{a}, \mathrm{b}}$ & $2.8 \pm 1.9^{\mathrm{B}}$ \\
EEM & 59 & $3.1 \pm 1.7^{\mathrm{b}}$ & $2.7 \pm 2.3^{\mathrm{B}}$ \\
Total & 209 & $3.6 \pm 2.1$ & $3.1 \pm 2.1$ \\
\hline
\end{tabular}

Values in the same columns with different superscripts are significantly different; ( ${ }^{\mathrm{a}, \mathrm{b}} P<0.05$; $\left.{ }^{\mathrm{A}, \mathrm{B}} P<0.01\right)$.

\section{PROSTAGLANDIN $\mathrm{F}_{2 \alpha}$ COMPROMISES DEVELOPMENT OF PRE-IMPLANTATION BOVINE EMBRYOS DURING COMPACTION}

\author{
F.N. Scenna, J.L. Edwards, and F.N. Schrick
}

Department of Animal Science, University of Tennessee, Knoxville, TN, USA. email: fschrick@utk.edu

Several studies have implicated prostaglandin $\mathrm{F}_{2 \alpha}$ (PGF) as a major embryotoxic factor during early embryonic development in cattle. Elevated uterine concentrations of PGF were negatively associated with embryo development, quality and pregnancy rates (Schrick FN et al. 1993 Biol. Reprod. 49, 617-621; Hockett ME et al. 1998 J. Anim. Sci. 76 (Suppl 1), 241 abst; Seals RC et al. 1998 Prostaglandins 56, 377-389). Moreover, 
addition of PGF to culture medium decreased hatching rates of compacted morulae (Scenna FN et al. 2002 Theriogenology 53, 512 abst) and decreased development of pre-compacted (16-32 cell) bovine embryos to blastocyst stage (Scenna FN et al. 2003 Theriogenology 59, 335 abst). Furthermore, administration of an inhibitor of PGF synthesis at the time of embryo transfer improved pregnancy rates in cattle (Schrick FN et al. 2001 Theriogenology 55, 370 abst). The objective of the current study was to identify the period of time during early embryonic development that is most susceptible to the deleterious effects of PGF. After in vitro maturation and fertilization of bovine oocytes, putative zygotes were cultured in KSOMaa plus 0.3\% BSA. On Day 4 post-insemination, pre-compacted (16-32 cell) embryos were removed from culture, evaluated for quality, and randomly assigned to one of the following treatments: 1 ) Control (KSOMaa plus $0.3 \%$ polyvinyl alcohol (KSOM-PVA; $n=470$ ) or 2 ) PGF-1 ( $1 \mathrm{ng} \mathrm{mL}{ }^{-1}$ PGF in KSOM-PVA; $n=473$; Scenna FN et al. 2003 Theriogenology 59, 335 abst). After $48 \mathrm{~h}$ of incubation in assigned treatments, assessment of development to compacted morula stage was determined. Thereafter, embryos were kept separate according to treatments, sorted by stage of development and quality, and randomly assigned to receive either Control (CON) or PGF-1 supplemented medium until assessment of blastocyst development on Day 9. This random sorting resulted in the formation of four treatment groups comprising the initial treatments and assigned treatments during Days 6-9 (CON-CON, $n=366$; PGF-CON, $n=226$; CON-PGF, $n=149$; PGF-PGF, $n=287$ ). Analyses were performed incorporating a randomized incomplete block design using mixed models of SAS (2000) to determine effects of PGF on Days 4-6, 6-9 and 4-9 of development. Data were also analyzed using chi-square. Addition of $1 \mathrm{ng} \mathrm{mL}{ }^{-1}$ of PGF to culture medium on Days 4-9 decreased the percentage of pre-compacted embryos reaching blastocyst stage (CON-CON, 47.8\%; PGF-PGF, 36\%; $P<0.05)$. Moreover, addition of $1 \mathrm{ng} \mathrm{mL}{ }^{-1}$ of PGF to the culture medium of pre-compacted bovine embryos on Days 4-6 of development decreased the percentage of compacted morulae on Day 6 (Control, 68.1\%; PGF-1, 60.5\%; $P=0.01$ ). However, the percentage of embryos developing to blastocyst was not decreased following addition of $1 \mathrm{ng} \mathrm{mL}^{-1}$ of PGF on Days $6-9$ of development (CON-CON, 47.8\%; CON-PGF, 42.6\%; $P>0.05$ ). Results suggest that morula stage embryos during compaction are most susceptible to deleterious effects of PGF.

\title{
140 A STUDY ON HINNY PRODUCTION FROM LOCAL JENNIES (EQUUS ASINUS) AND STALLIONS (E. CABALLUS) IN ETHIOPIA: NORMAL OFFSPRING PRODUCED
}

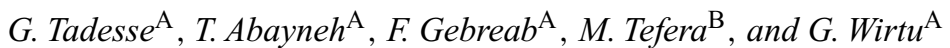 \\ ${ }^{A}$ Faculty of Veterinary Medicine, Addis Ababa University, Debre Zeit, Ethiopia; ${ }^{B}$ Mekelle University College, Mekelle, Ethiopia. \\ email: gwirtu1@1su.edu
}

Domestic equids, consisting of 5 million donkeys, 1 million horses and 0.6 million mules, play important roles in Ethiopia's economy by providing services in transportation and traction sectors. In spite of the large equine population and the common use of mules (jack $\times$ mare), the opposite hybrid, hinny (stallion $\times$ jenny) is uncommon. Compared to using mules or either parent, hinnies could provide certain economic and environmental advantages. Considering the large female donkey population, it may be easier and more affordable to produce hinnies than mules. Moreover, hinnies are better than donkeys in draft performance. Thus, using hinnies could help in reducing the large donkey population and hence their negative environmental effect. However, there is no recorded attempt of hinny production in Ethiopia. Although data from controlled experiments are limited, interspecies breeding to produce hinnies is less successful than attempts to produce mules mainly because hinnies are thought to be less fertile. In the present study, adult and cycling Abyssinian jennies were divided into two groups ( $n=10$ each) for natural breeding with three jacks (Jack group) or four stallions (Stallion group). During a period of two years, data on intraspecies and interspecies courtship behavior, mating activities, conception and foaling were recorded. Data were collected mainly by visual observation. Pregnancy was also diagnosed by palpation per rectum at 60 to 90 days after service. Mating was conducted during natural or $\mathrm{PGF}_{2 \alpha}$-induced estrus. Data on the number of services per conception, number of pregnancies and foaling were compared using chi-square or Fisher's test. Jennies in estrus showed overt sexual interest in jacks, stallions and even female herdmates. Two stallions showed sexual interest in jennies; however, only one mated successfully and hence jennies in heat were exposed to this male. In the Jack group, 9 of the 10 jennies conceived (with 27 cycles bred, or 3 cycles/pregnancy). One pregnant jenny died of unrelated causes. Of the remaining 8 pregnant jennies, 3 aborted and 5 delivered live foals. In the stallion group, 3 of the 10 jennies conceived (with 47 cycles bred, or 15.7 cycles/pregnancy). Two of the three females aborted and one delivered a live female foal. The pregnancy rates between the two treatments $(90 \%$ v. $30 \%)$ were significantly different $(P=0.02)$; however, treatment did not affect $(P>0.05)$ foaling rates $(63 \% \mathrm{v} .33 \%)$ or abortion rates $(38 \% \mathrm{v}$. $67 \%$ ). Abortion occurred at 192 to 254 days (Jack group) and 147 and 159 days (Stallion group) of gestation. Gestation lengths of $370.2 \pm 4.5 \mathrm{v} .330$ day and foal body weight of $13.3 \pm 1.0$ v. $16 \mathrm{~kg}$ were recorded in the Jack and Stallion groups, respectively. Foaling did not require assistance in either group. We have demonstrated the possibility of hinny production using local jennies and stallions. The main limitations to hinny production were poor sexual desire of stallions towards jennies and also low conception rates after interspecies mating. The latter also cast doubts on the potential of alternative approaches (e.g. artificial insemination) to circumvent the behavioral barrier to interspecies breeding. We would like to thank RPSUD for funding this project and Dr. Azage Tegegne for overall assistance.

\section{EFFECT OF NUMBER OF LAMBS, THEIR SEX AND BIRTH WEIGHT ON OVINE PREGNANCY-ASSOCIATED GLYCOPROTEIN (OVPAG) CONCENTRATIONS}

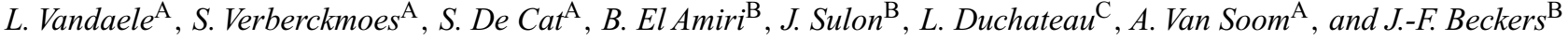 \\ ${ }^{A}$ Department of Reproduction, Obstetrics and Herd Health, Faculty of Veterinary Medicine, Ghent University, 9820, Belgium; ${ }^{B}$ Department of \\ Physiology of Reproduction, Faculty of Veterinary Medicine, University of Liège, 4000, Belgium; ${ }^{\mathrm{C}}$ Department of Physiology, Biochemistry and \\ Biometrics, Faculty of Veterinary Medicine, Ghent University, 9820, Belgium. email:stevenv.verberckmoes@rug.ac.be
}

Early pregnancy detection and prediction of the number of lambs would be profitable for sheep breeders, as this enables nourishment of pregnant ewes to their individual needs. Nonpregnant ewes can be separated and sold before winter. Prediction of sex is interesting for the curiosity of impatient breeders. Early pregnancy detection (before 45 days after mating) by means of ovine pregnancy-associated glycoproteins (ovPAGs) has proved to be a more reliable test than the commonly used transrectal ultrasound. The concentration of ovPAG has been claimed to be related to the number 
of lambs, their sex and birth weight, but contradictory results were obtained in different small-scale studies. In this study the correlation between number of lambs, their sex and birth weight and the ovPAG concentration in the serum of the ewes was examined. In a field trial, 160 and 70 ewes of the Texel and Suffolk breed, respectively, housed on 6 different farms, were synchronized by means of intravaginal sponges impregnated with $40 \mathrm{mg}$ cronolone (Chronogest ${ }^{\circledR}$, Intervet, Boxmeer, The Netherlands). At the moment of synchronisation (T0) and at 25 (T25), 35 (T35) and 45 (T45) days after mating or artificial insemination, blood samples were taken by jugular vein puncture. A heterologous radioimmunoassay (RIA) was used to determine the ovPAG concentration. In the heterologous RIA boPAG molecules were used as tracer, and ovPAG molecules as standard, while rabbit antibodies against ovPAG were used as antiserum. At parturition, number, sex and birth weight of the lambs were registered and their effect on ovPAG concentrations was statistically evaluated. No significant difference in ovPAG concentration was found between ewes pregnant of a single male or female lamb $(P=0.29)$. ovPAG concentrations were affected by the total birth weight $(P<0.05)$. In ewes pregnant with multiples, the ovPAG concentrations were higher $(P<0.01)$ than in ewes pregnant with singles at T25, T35 and T45, respectively. Because ovPAG concentrations were affected by the farm, it was impossible to predict the number of lambs by the ovPAG level. In conclusion, ovPAG concentrations were not affected by the sex of the lamb. However, ovPAG concentrations were related to the total birth weight. Within the farm, increased ovPAG concentrations may indicate pregnancy of multiples.

\title{
142 DETECTION OF LATE EMBRYONIC MORTALITY BY MEANS OF OVINE PREGNANCY ASSOCIATED GLYCOPROTEINS
}

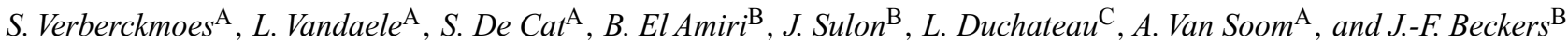 \\ ${ }^{\mathrm{A}}$ Department of Reproduction, Obstetrics and Herd Health, Faculty of Veterinary Medicine, Ghent University, 9820 , Belgium; ${ }^{\mathrm{B}}$ Department of \\ Physiology of Reproduction, Faculty of Veterinary Medicine, University of Liège, 4000, Belgium; ${ }^{\mathrm{C}}$ Department of Physiology, Biochemistry and \\ Biometrics, Faculty of Veterinary Medicine, Ghent University, 9820, Belgium. email: stevenv.verberckmoes@rug.ac.be
}

In sheep, conception rates of $80 \%$ are obtained after first mating. Some of the ewes that were not pregnant may have conceived, but underwent embryonic mortality. Embryonic mortality can be distinguished as early (EEM) or late (LEM) embryonic mortality. When EEM occurs, sheep return to estrus $17 \pm 2$ days after mating, which makes the detection of EEM very difficult. Because determination of ovine pregnancy-associated glycoprotein (ovPAG) concentration can be used for pregnancy diagnosis from Day 25 of conception, with a specificity and sensitivity of $100 \%$ and $99 \%$, respectively, it possibly could be used for detection of LEM (Verberckmoes et al., 2003. Pregnancy diagnosis in sheep by means of ultrasound and ovine pregnancy associated glycoproteins (ovPAG), 10th International Symposium on Veterinary Epidemiology and Economics (ISVEE 10), 17-21 November, 2003.). Therefore, in this study the prevalence of LEM and the usefulness of ovPAG concentration for the detection of LEM were examined. In a field trial, serum samples of 160 Texel and 127 Suffolk ewes were collected at the moment of estrus synchronization (T0), and at 25 (T25), 35 (T35), and 45 days (T45) after mating. Concentrations of ovPAG were determined by means of homologous RIA using ovine PAG as standard and tracer, and rabbit antibodies against ovPAG as antiserum. Ewes were considered as being pregnant when ovPAG concentrations were higher than $2 \mathrm{ng} \mathrm{mL}^{-1}$. The F-test in a mixed model with ewe as random effect was used to compare the mean PAG concentrations. Of the 287 ewes examined, 5 Suffolk and 2 Texel ewes showed an abnormal PAG profile which was indicative of LEM. The average ovPAG concentration of the 7 former ewes at T25 was $5.6 \pm 2.0 \mathrm{ng} \mathrm{mL}^{-1}$, which indicates that they were pregnant. However, in contrast to the normal pregnant ewes, they had significantly lower ovPAG concentrations at T35 $\left(2.8 \pm 1.5 \mathrm{ng} \mathrm{mL}^{-1}\right.$ v. $\left.9.5 \pm 2.3 \mathrm{ng} \mathrm{mL}^{-1}\right)$ and T45 $(0.9 \pm 0.3 \mathrm{ng} \mathrm{mL}-1$ v. $9.0 \pm 1.9 \mathrm{ng} \mathrm{mL}-1)$ $(P<0.01)$, and they did not lamb at $145 \pm 5$ days after mating. In conclusion, late embryonic mortality occurred in $2 \%$ of the ewes. Determination of the ovPAG concentration by means of homologous RIA is a useful tool for the detection of LEM in sheep. 